\title{
Caleidoscópio
}

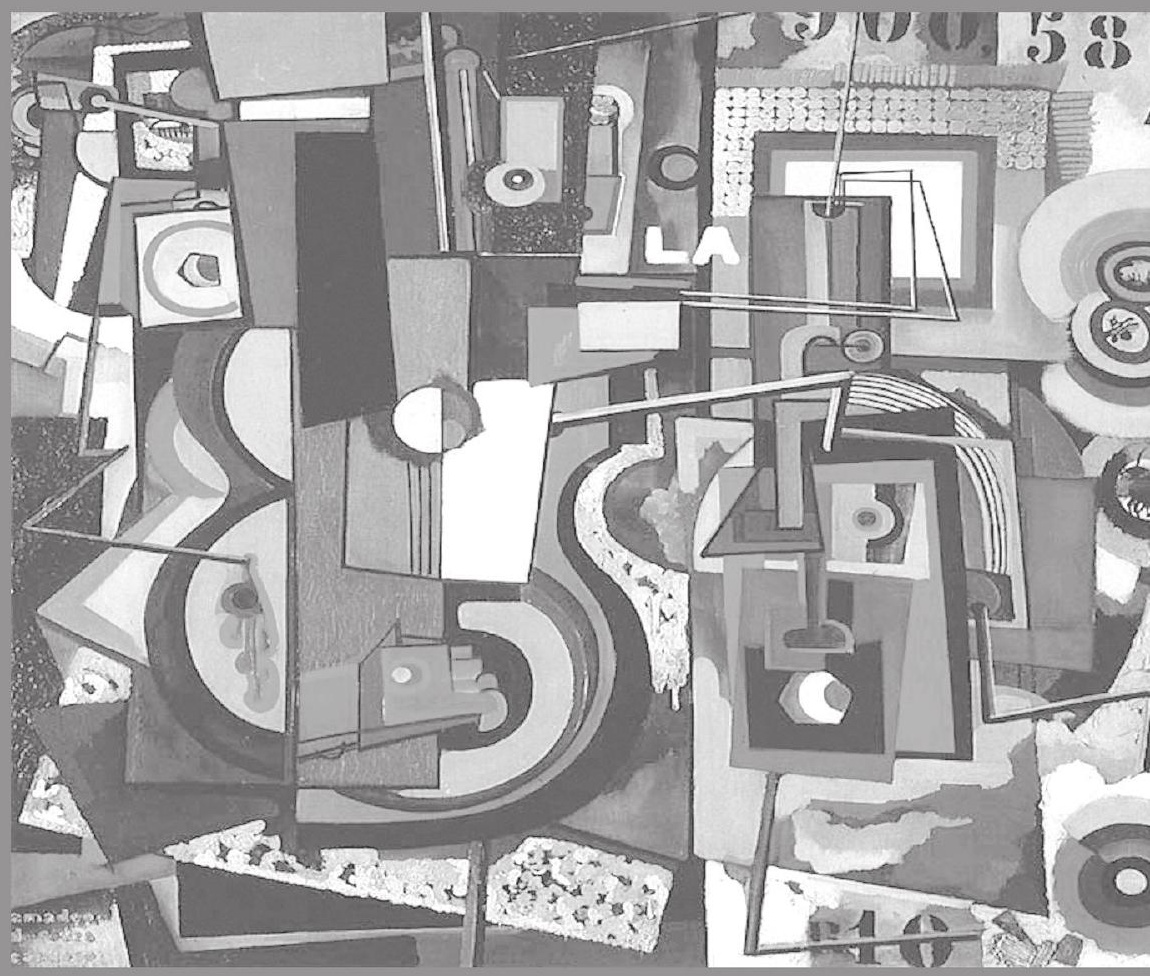





\section{DAS ARTICULAÇÕES ENTRE CORPO E EDUCAÇÃO FÍSICA: PISTAS PARA PENSAR}

ILEANA WeNETZ*

Priscila Gomes Dornelles ${ }^{* *}$

$\mathcal{N}$

a cultura contemporânea, os corpos assumiram maior centralidade e importância social. Tornaram-se lugar de transformação, construção dos sujeitos e, sobretudo, de apresentação inequívoca da identidade. A cultura do movimento humano participa, junto com outras instâncias educativas, desse processo de construção.

Autores e autoras, estudiosos e estudiosas dos caminhos históricos do corpo e/ou da Educação Física, como Carmem Lúcia Soares (2001), Silvana Goellner (2003) e Carlos Herold Junior (2005), bem como Denise Sant'Anna (2001), assinalam o final do século XIX e o início de século XX como demarcação temporal da configuração de uma nova preocupação social. É uma preocupação que atua individualmente, mas que toma como foco o coletivo, a educação dos corpos. Discursos médicohigienistas, de saúde, de ordenação e produtividade da população passam a "(...) constituir um conjunto de dispositivos e saberes que atuam no corpo" (Goellner, 2003, p. 35), posicionando os exercícios físicos como uma necessidade imprescindível no contexto social, inclusive na escola. Esta forma de educação do corpo (o que, posteriormente, se constituirá como educação física) entra pela porta do futuro no espaço

* Doutora em Ciências do Movimento Humano e participante dos Grupos de Estudos Socioculturais em Educação Física (Gesef) e do Grupo de Estudos em Educação e Relações de Gênero (Geerge/Faced), ambos da UFRGS. E-mail: ilewenetz@gmail.com

** Doutoranda no Programa de Pós-Graduação em Educação da UFRGS e professora do Centro de Formação de Professores da Universidade Federal do Recôncavo da Bahia (UFRB). E-mail: prisciladornelles@gmail.com 
Das articulações entre corpo e educação física: pistas para pensar

escolar como garantia dos destinos e como construção de uma nova geração. Contudo, nesse entremeio, nesse processo, está o corpo que, como comenta Sant'Anna (2001, p. 107), se torna "a principal matéria-prima da educação do ser humano, mas, ao mesmo tempo, o seu mais importante produto".

Os estudos das práticas corporais inseridas na cultura do movimento humano permitem compreender as relações dos sujeitos com seu próprio corpo, ao focarmos o olhar nos diferentes significados sociais atribuídos aos corpos na sociedade. Entendemos que analisar, historicizar e problematizar esses sentidos permitem romper com uma perspectiva biológica de compreensão do corpo e com certa densidade na compreensão de como alguns discursos o constituem e o significam em um determinado tempo e espaço.

Assim, como propomos no título desta seção, uma pista para pensar a articulação entre corpo e educação física na contemporaneidade é olhar para outros momentos, tempos e espaços, outras marcas, outros corpos e significados como um caminho estratégico para estranhar, questionar e duvidar da concepção e do caráter natural que uma prática corporal, inserida na área da educação física, pode adquirir nos dias de hoje. Entretanto, ao propor apresentar e problematizar o corpo, não buscamos a origem para linearmente explicar sua continuidade, mas aventurar-nos na constituição de amarrações culturais para questionar o presente como produto de uma construção imbricada em relações de poder-saber.

Assinalamos também, como segunda pista, que o enunciado das diferenças naturais entre homens e mulheres esteve atravessando diferentes discursos, como o religioso e o biológico, e sendo por eles constituído. O último caracteriza-se por conformar e atribuir às diferenças biológicas papel determinante na demarcação das (im)possibilidades sociais dos sujeitos. Ou seja, em função das características biológicas dos corpos e, de forma ímpar, em função das suas marcas sexuais, há uma articulação discursiva que, de certa forma, configura uma rede de limites e possibilidades dos sujeitos, especialmente em relação às práticas corporais, constituindo destinos diferenciados para os corpos de homens e mulheres.

Tais marcas podem ser observadas no corpo, um corpo sempre a ser modificado, imperfeito, um corpo no rascunho (Le Breton, 2003), 
em que, além de múltiplas formas de controle e regulação, também diferentes vivências podem ser percebidas. O corpo torna-se lugar de diferentes identidades que se compactuam ou disputam. Identidades sociais de gênero, sexualidade, raça/etnia, por exemplo, "apresentamse" no corpo. A sexualidade, nesse viés, não se constitui como uma escolha pessoal, como uma questão social e política (Louro, 2001).

Problematizar essas noções de corpo, no limite das suas identidades, nos espaços do cotidiano, em nosso dia a dia, produz um estranhamento daquelas práticas tão familiares - estranhamento que, como dizem Meyer e outros (2004, p. 12), permite "politizar os temas vinculados ao corpo em sua articulação com gênero e sexualidade, pois trazem para o centro do debate questóes de poder, de identidade e de política”. Além disso, pode-se dizer que a sexualidade é construída em um processo que dura toda a vida (Weeks, 1999).

Considerando os aspectos anteriormente mencionados e a multiplicidade de significados atribuídos ao corpo, observando a heterogeneidade de marcas, tempos, espaços dentro ou fora da escola, no cotidiano, nas práticas corporais e esportivas, por fim, perguntamos: do que falamos quando falamos do corpo?

Este número dos Cadernos Cedes reúne artigos que apontam uma série de caminhos investigativos e pistas para pensarmos o corpo na contemporaneidade. Esperamos que esta coletânea, ao fim e ao cabo, sinalize a leitores e leitoras a necessidade de refazermos a questão que acabamos de colocar, esboçando e ensaiando diversas possibilidades teóricas e analíticas que nos permitam continuar a refletir sobre corpo, educação física e sociedade.

\section{Referências}

GOELLNER, S. A produção cultural do corpo. In: LOURO, G.L.; NECKEL, J.; GOELLNER, S. Corpo, gênero e sexualidade: um debate contemporâneo na educação. Petrópolis: Vozes, 2003. p. 28-40.

HEROLD JUNIOR, C. Da instrução à educação do corpo: o caráter público da educação física e a luta pela modernização do Brasil no século XIX (1880-1915). Educar, Curitiba, n. 25, p. 237-255, 2005. 
LE BRETON, D. Adeus ao corpo: antropologia e sociedade. Campinas: Papirus, 2003.

LOURO, G.L. Pedagogias da sexualidade. In: LOURO, G.L. (Org.). O corpo educado: pedagogias da sexualidade. 2. ed. Belo Horizonte: Autêntica, 2001. p. 7-34.

MEYER, D.; SOARES, R. (Org.). Corpo, gênero e sexualidade. Porto Alegre: Medição, 2004.

SANT'ANNA, D.B. Educação física e história. In: CARVALHO, Y.M.; RUBIO, K. (Org.). Educação física e ciências humanas. São Paulo: Hucitec, 2001. p. 105-114.

SOARES, C.L. Educação física: raízes europeias e Brasil. 2. ed. Campinas: Autores Associados, 2001.

WEEKS, J. O corpo e a sexualidade. In: LOURO, G.L. (Org.). O corpo educado: pedagogias da sexualidade. Belo Horizonte: Autêntica, 1999. 